\title{
An activity-dependent computational model of development of the retinotopic map along the dorsoventral axis in the primary visual cortex
}

\author{
Ryan Thomas Philips, V Srinivasa Chakravarthy* \\ From The Twenty Third Annual Computational Neuroscience Meeting: CNS*2014 \\ Québec City, Canada. 26-31 July 2014
}

Primate vision research has shown that in the retinotopic map of the primary visual cortex, eccentricity and meridional angle are mapped onto two orthogonal axes [1]: whereas the eccentricity is mapped onto the nasotemporal axis, the meridional angle is mapped onto the dorsoventral axis. Such a map has been approximated by a complex log map [1]. While the development of the map along the nasotemporal axis is controlled by a combination of EphA-ephrin-A signaling as well as spontaneous retinal waves; the mechanisms involved in the map formation along the dorsoventral axis are still unknown [2]. Neural models with correlational learning have successfully explained other visual maps like orientation maps and ocular-dominance maps. No such network models of retinotopic map development exist. In this paper we propose an activity based model which simulates the largescale development of the retinotopic map along the dorsoventral axis. The architecture consists of a LISSOM (Laterally Interconnected Synergetically Self Organizing Map) [3] with 2 layers; representing the retina, and the V1 respectively (see Figure 1A). At each time step, each neuron in V1, combines the afferent activation $\left(\zeta_{r 1, r 2}\right)$ along with its lateral excitations and inhibitions $\left(\eta_{k l}\right)$ from the previous time step.

$$
\eta_{i j}(t)=\sigma\left(\sum_{r 1, r 2} \zeta_{r 1, r 2} \mu_{i j, r 112}+\gamma_{E} \sum_{k, l} E_{i j, k l} \eta_{k l}(t-1)-\gamma_{I} \sum_{k, l} I_{i j, k l} \eta_{k l}(t-1)\right)
$$

The afferent $\left(\mu_{i j, r 1 r 2}\right)$, lateral excitatory $\left(E_{i j, k l}\right)$ and lateral inhibitory $\left(I_{i j, k l}\right)$ weights adapt based on a normalized Hebbian mechanism. The input to the retinal layer consists of rectangular bars of varying dilation and rotation; since images on the retina could be considered as different projective transforms of the objects seen. The outer boundary of the V1 layer is also constrained to

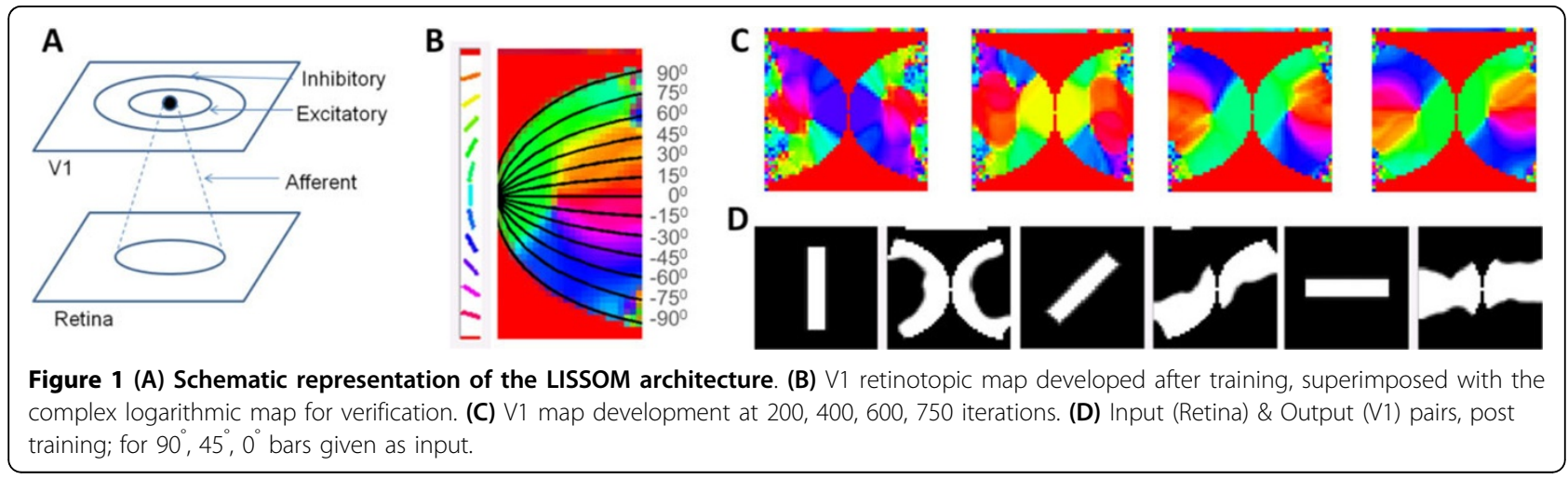

\footnotetext{
* Correspondence: srinivasa.chakravarthy@gmail.com

Department of Biotechnology, Indian Institute of Technology Madras,

Chennai 600036, Tamil Nadu, India
} 
simulate the flattened V1 surface area (see Figure 1B). After training for 750 iterations (see Figure 1C), it may be observed in the developed map that eccentricity is mapped along the $\mathrm{x}$-axis while the meridional angle is mapped along the $y$-axis, an organization that bears strong resemblance to the complex logarithmic map [1] (see Figure 1B, Figure 1D).

\section{Conclusions}

A neural activity based model for the development of retinotopic map along the dorsoventral axis is demonstrated and the final map developed is compared with experimental results approximated by the complex log map equations.

Published: 21 July 2014

\section{References}

1. Schwartz EL: The development of specific visual connections in the monkey and the goldfish: Outline of a geometric theory of receptotopic structure. Journal of Theoretical Biology 1977, 69(4):655-683.

2. Cang J, Niell CM, Liu X, Pfeiffenberger C, Feldheim DA, Stryker MP: Selective disruption of one Cartesian axis of cortical maps and receptive fields by deficiency in ephrin-As and structured activity. Neuron 2008, 57(4):511-523.

3. Bednar JA: Topographica: building and analyzing map-level simulations from Python, $\mathrm{C} / \mathrm{C}++$, MATLAB, NEST, or NEURON components. Frontiers in neuroinformatics 2009, 3.

doi:10.1186/1471-2202-15-S1-P189

Cite this article as: Philips and Chakravarthy: An activity-dependent computational model of development of the retinotopic map along the dorsoventral axis in the primary visual cortex. BMC Neuroscience 2014 15(Suppl 1):P189.

\section{Submit your next manuscript to BioMed Central} and take full advantage of:

- Convenient online submission

- Thorough peer review

- No space constraints or color figure charges

- Immediate publication on acceptance

- Inclusion in PubMed, CAS, Scopus and Google Scholar

- Research which is freely available for redistribution

Submit your manuscript at www.biomedcentral.com/submit 